\title{
FUNDAMENTALS OF PROMOTION OF SPORTS AND COMPETITIONS AND PHYSICAL TRAINING AMONG SCHOOL STUDENTS
}

\author{
Islomkhoja Azimkhojaevich Islamov
}

Lecturer Department Of Culture Fergana State University Physical, Uzbekistan

\section{ABSTRACT}

The article analyzes the importance of sports training, competition regulations, the preparation of regulations, compliance with medical hygiene and safety requirements in the preparation of competition venues, coverage of competitions, medical care and the importance of physical education in student development.

KEYWORDS :- Sports, competitions, qualifiers, national teams, charter, program, winners, awards, medical supervision, injury prevention, physical education.

\section{INTRODUCTION}

Sports training sessions are organized for students in any sport at the educational institution or in the living quarters. Sometimes such classes are attended by professors, teachers and staff. Sports training groups can consist of groups of runners, swimmers, athletics, wrestling and sports games. Sports training groups are led by qualified sports coaches. The training will be attended by highly qualified athletes who are members of national teams, as well as athletes in basic training.

Sports competitions are one of the most effective forms of organizing mass physical culture and sports fitness activities. Athletes will compete in the first qualifying round. At all levels of educational institutions, students are organized among students, workers, military units, police and emergency services, the population of all ages in the residences. At this stage, the greatest popularity of the competitions is ensured. At the next stage, district, regional and city championships will be held. The winners of the competitions will have the opportunity to participate in the Republican championships of the finals. The winners of the republic will be selected to the national team and will have the honor of defending the prestige of our country at international sports competitions, world and continental championships, the Olympic Games [1].

All sports competitions are divided into individual, individual - group, group championships. Competitions come in the form of one-time, one-day and multi-day, traditional, official, friendly matches, tournaments and open championships.

Sports competitions and sports festivals play an important role in the lives of students. Sports competitions help to assess the sports skills of student-athletes, qualify for national teams, as well as popularize physical education and sports fitness activities among all students. Higher education strengthens the bonds of friendship and aspect between students. It will be a great 
help in forming relationships for future study and collaboration in cocktail activities. In the fifties of the last century in our country it has been a common tradition to hold Spartakiad games among students. Such competitions were organized mainly in sports, wrestling, athletics, swimming, tennis, chess and checkers, and marathon running. Since 2000, competitions in many sports have been organized among students and are called Universiade competitions. Then it became a tradition to organize sports games of harmoniously developed generation and sports competitions Umid Niholli. Students who successfully participated in the competitions began to have the opportunity to participate in international sports competitions at the Universiade. Many of our compatriots have also successfully participated in international Universiade competitions.

One of the main factors in the mass organization of sports competitions is a high level of organization. Planning of competitions, selection and preparation of venues and locations of competitions, development of competitions program and regulations, formation of the organizing committee of competitions, selection of judges, promotion and propaganda of competitions through mass media, preparation of advertisements and posters [2].

Calendar plans of sports competitions in educational institutions are developed by the staff of the sports association in collaboration with the staff of the Department of Physical Education. Competition calendar plans are developed for the duration of one academic year. The responsible representative of the Sports Association distributes the competition plans to all faculties, departments and divisions. All students, professors, teachers and staff will be introduced to the competition schedule. Visual information is posted on the bulletin board as a poster.

\section{Materials AND MEthodS}

The regulations of sports competitions are the main document of competitions, which contain all the instructions for the competition. The organizers of the competitions, the chief referee, the jury, the teams, the captains of the teams, the representatives of the teams, the participants of the competition act in accordance with the regulations during the competition.

In developing the rules of the competition, the capabilities of all teams and athletes are taken into account. In developing the rules of competitions organized in the educational institution, the staff of the sports association cooperates with the heads of sports clubs, the board of coaches, professors and teachers of the Department of Physical Education. The rules of competitions are approved by the head of the university, chairmen of trade unions and sports associations. The rules of the competition must be communicated to all teams one month before the competition.

The organizers of the competition will develop an action plan for the preparation and conduct of the competition. A competition advocacy group will be formed, whose tasks will be defined. Ensuring the preparation of the competition venue for sports facilities, gyms, stadiums and arenas, as well as ancillary rooms, to ensure that they meet the rules of hygiene and technical safety. Formation of the jury and medical staff, control over their duties [3].

An action plan for medical, hygienic and technical safety of competitions will be developed. In competitions of any form and type, a team of doctors works to ensure that the competition venues meet medical and hygienic requirements. Competitors will also be responsible for protecting their health and providing first aid for injuries during the competition. 


\section{Results AND DISCUSSION}

The staff of doctors will consist of members of the medical department of the higher education institution. From them the chief physician of the competition is appointed, who is the deputy chief referee of the competition. When the jury accepts applications from teams to participate in the competition, only the doctor will accept applications stamped that the athlete is healthy. Applications that do not meet this requirement will not be accepted and athletes will not be admitted to the competition. Accordingly, no objections will be accepted in this process and the decision of the jury will be final. The competition organizers and the jury must create all the necessary conditions to prevent accidents and emergencies during the competition. According to the rules of the competition, the organizers of the competitions are responsible for preventing injuries during the competition process.

The jury will be approved a few days before the competition. The panel of judges is composed of the chief referee and his deputies. Meetings and discussions will be held to explain the tasks of the judges in the competition, competition plans and their content, the articles of the rules of the competition. The jury will consist of the chief referee and his deputies for medical care and economic affairs, the secretary of the competition and his deputies, the referee of time control, the referee of the finish line, equipment, groups, lines, reserve referee and informant referees. Judges, in accordance with their experience and qualifications, will have the ranks of ordinary judges, judges of the first category, judges of the republican category, judges of the international category. In setting national, continental and world records, it is important that the judging panel is complete and that their levels are high. Regardless of the type and category of competition, the judges must be in their specially designated clothing.

Material and economic support of the competition process greatly contributes to the repair of sports facilities in accordance with the requirements of the competition, the provision of modern sports equipment and competition equipment. Transportation of teams, athletes and team representatives, referees and participants of the competition, their accommodation in hotels, catering and promotion of competitions, preparation of posters, invitations and spectacle tickets, purchase of gifts, medals and certificates, the organization of concerts at the closing ceremonies, the tasks of which are also performed at the expense of economic provision. Therefore, the competition organizers, in cooperation with sponsors and trade unions and responsible organizations, develop and approve the amount of expenses for the competition. The costs of competitions can include the salaries of referees and support staff, as well as the achievements of athletes [4].

Sports classes and competitions not only bring up young people as physically fit and spiritually mature people, but also positively solve the task of training highly qualified athletes in sports.

The role of physical education and sports in the health of students is becoming increasingly important. Much attention has been paid to the upbringing of the population of our country, as well as the health of the younger generation as physically fit people. During this period, many higher and secondary special educational institutions of the country began to organize courses and departments for the training of physical education specialists. In 1958, the Faculty of Physical Culture was established at the Pedagogical Institute in Andijan under the Faculty of Biology. From the 1959-1960 academic year it began to function as an independent faculty. Over the years, the faculty has been led by many 
mature professionals. To date, more than 1,000 students have graduated from the faculty. Among them are many winners of national competitions and world champions, winners of more than 100 international competitions and many champions. [5]

During the years of independence, the material base of the faculty has been strengthened. A swimming pool, tennis and wrestling halls, a football field, and athletics fields were established and renovated. Andijan State University sports facilities were built and renovated in accordance with modern requirements. Currently, the Faculty of Physical Culture has a gym, wrestling and athletics hall, swimming pool, shower, sauna, restrooms, football stadium, athletics stadium, throwing and jumping sectors, general physical training, mini football, handball, volleyball and tennis courts. [6]

Students are taught in the form of theoretical and practical lessons in gymnastics, athletics, swimming, volleyball, basketball, handball, movement games, sports and national wrestling, athletics and tourism. In addition, the club organizes technical, tactical and physical training in sports such as gymnastics, athletics, weightlifting, boxing, swimming, volleyball, basketball, handball, wrestling, football. [7]

We know that regular exercise on a regular basis, walks in the fresh air in the evening, taking exercise therapy leads to positive morphofunctional changes in the body's systems, disease resistance is formed and increases. The results of the study show that the factors that negatively affect the level of physical development of students and the formation of theoretical and practical knowledge of science are alcohol consumption, smoking, lack of exercise, malnutrition and leisure.

Adherence to a healthy lifestyle, exercise and sports, quality and timely nutrition, proper rest, organization of exercise procedures under the influence of water, sun and air, along with the physical development of students, increase the level of theoretical and practical knowledge. can be a key factor in becoming an expert. It is the duty of physical education and sports specialists to organize a healthy lifestyle among students, to involve them in physical culture and sports, to inculcate healthy lifestyle skills in their daily lives. [8]

\section{Conclusion}

In the process of physical education, teachers solve the tasks of the stages of education using different methods of teaching in the process of teaching students movements and teaching exercise techniques. In physical education, it can be seen that the strengthening and repetition of exercises many times on the basis of different requirements is a guarantee of perfect mastery of exercise techniques. As a result, movement skills and abilities are improved.

In the process of physical education, physical qualities, moral and spiritual qualities, community, friendship, cooperation, courage, perseverance and patriotism are brought up together. Students also develop the qualities of initiative and activity in following the rules of the agenda. [9]

\section{ReFERENCES}

1. Scientific research in the field of sports. Kerimov F.A. Tashkent 2003.

2. Theoretical bases of sports training. R.S.Salomov. Tashkent 2005.

3. Theory and methods of sports for children and adolescents. T.S.Usmonxujaev. Tashkent 2005. 
4. The theory of development of physical abilities of young athletes. O. V. Goncharova; Tashkent 2005.

5. R.S.Salomov. Theoretical bases of sports training. Tashkent, 2005.

6. M.S.Axmatov. Effective management of mass sports rehabilitation in the system of continuing education. Tashkent, 2005.

7. Karimov F.A. Theory and methodology of wrestling. Tashkent, 2005.

8. Qurbanov Sh. A.Qurbonov. Physiological basis of exercise. Tashkent, 2003.

9. K.F.Bakutine. N.B.Pavlova. Materials for physical education lessons. Tashkent, 1970.

10. Siddikov, I. В. (2019). Философскопедагогические аспекты развития интеллектуальной культуры студентов. Вестник Ошского государственного университета, (3), 38-42. 